\title{
Distance learning in the era of COVID-19
}

\author{
Samantha L. Schneider ${ }^{1} \cdot$ Martha Laurin Council ${ }^{1}[0$
}

Received: 16 April 2020 / Accepted: 27 April 2020 / Published online: 8 May 2020

(c) Springer-Verlag GmbH Germany, part of Springer Nature 2020

\begin{abstract}
The novel coronavirus (SARS-CoV-2) pandemic has necessitated a dramatic shift in how our dermatology residents and fellows are educated. Distance or online learning has become the norm, and several national and international academic societies have combined resources to assure that continuing medical education occurs during this difficult time. The purpose of this communication is to review select online resources available to dermatology trainees and to encourage our colleagues to continue to advance our specialty through distance learning.
\end{abstract}

Keywords COVID $\cdot$ Learning $\cdot$ Education $\cdot$ Distance

There is no question that the novel coronavirus (SARSCoV-2) outbreak causing the disease known as COVID-19 has dramatically changed lives throughout the world. Originating in China, the first case of pneumonia was reported on December 8, 2019 [1] and identified on January 7, 2020. It has since disseminated across the world. This global pandemic has necessitated a dramatic paradigm shift in terms of how we interact with each other. Many offices have either made the transition to teledermatology or greatly reduced their patient volumes to accommodate the widely accepted "social distancing" recommendation by the World Health Organization and the United States Centers for Disease Control and Prevention [2, 3]. Hospitals and practices are developing screening and contingency plans for clinical medicine. But what about the education of our colleagues and our trainees during this time of uncertainty?

Distance or online learning is not a new concept; however, for many of us as physicians-particularly academic physicians-it is a shift away from our traditional classroom teaching model for trainees. In 2004, Drs. Cook and Dupras published an article explaining the most effective way to create an online learning platform to be used in medicine. They highlight the importance of a user-friendly and intuitive website design that is well maintained, as well as the integration of self-assessment features to ensure that learners are properly engaging in the material [4]. More recently,

Martha Laurin Council

mcouncil@wustl.edu

1 Washington University in St. Louis, St. Louis, MO, USA
Virginia Gewin described helpful tips in the transition to online learning [5]. She notes the importance of creating much more focused lessons for online learning that highlight a few main points. She notes the utility of live-video conferencing for follow-up to the previously described selflearning module, but states that live conferencing should not be used for all educational activities due to poor connections and overuse. Cook, Dupras, and Gewin all agree that the most effective platforms enabled learners to interact with the material. Using this method, students can pursue the information at their speed and engage in the course through feedback and commentaries $[4,5]$. These concepts are imperative to keep in mind as we transition as a specialty to online instruction. This is a unique opportunity to consider long-term plans for how to educate residents and maintain continuing medical education (CME) as a specialty.

Within our greater dermatology community, academic programs and larger societies have been stepping up to develop content for trainees and seasoned practitioners alike. The American Academy of Dermatology (AAD) is continuing to email out the questions of the week and record new Dialogues in Dermatology podcasts. The American Society for Dermatologic Surgery (ASDS) has hosted several webinars on timely topics such as financial wellness and updates in the legislature specific to COVID-19. Additionally, the ASDS continues to host a monthly surgical journal club during the pandemic, with plans to expand educational opportunities online during the coming weeks and months. The American College of Mohs Surgery (ACMS) has put out a call to fellows-in-training to create PowerPoint presentations 
with audio overlay for inclusion in an online database. The ACMS has also provided fellows-in-training with information about an online resource entitled "MDLive Online Dermatology Programs" (available at mdlive.net), which, in partnership with the University of California, Irvine, provides learners with a variety of courses ranging from dermatologic surgery to lasers and cosmetics.

This pandemic is a call to action for all dermatologists and dermatologic surgeons to consider how we can push our specialty forward. It is amazing to see what we are already dreaming of creating, but we can do and create more. Would not it be great if we could develop an online learning platform to supplement resident education? A place where residents could go to hear experts in the field discuss interesting cases that they may never see in training or teach pearls about the nuance of the physical examination via kodachromes. A platform where we could be sure, as a specialty, that the future of our field is obtaining a strong foundation in all pillars of dermatology: medical, pediatric, cosmetic, and procedural. In addition, once such a platform is in place, the possibilities of its application are incredible.

There will be a day when we all gather in person again. Such an online platform would never replace the need for live education of residents and dermatologists but it is such an important adjunct. For those of us continuing to take care of patients during these uncertain times, please continue to serve our patients and prevent them from inundating the hospitals and emergency departments. For those of us who have more time on our hands, this is an invitation to consider what you have to offer to our specialty. Reach out to one of our organizations and see how you can help. Let us see what we can accomplish together.

Conflict of interest Samantha Schneider has no financial conflicts of interest to disclose. M. Laurin Council has served as a consultant for Sanofi-Genzyme/Regeneron.

\section{Reference}

1. Wu Z, McGoogan JM (2020) Characteristics of and important lessons from the coronavirus disease 2019 (COVID-19) outbreak in china: summary of a report of 72314 cases from the Chinese center for disease control and prevention. JAMA. https://doi. org/10.1001/jama.2020.2648

2. CDC. Public Health Recommendations after Travel-Associated COVID-19 Exposure. Centers for Disease Control and Prevention. Coronavirus Disease 2019 (COVID-19). https://www.cdc. gov/coronavirus/2019-ncov/php/risk-assessment.html. Accessed Apr 22020

3. WHO. Coronavirus disease (COVID-19) advice for the public. World Health Organization. Coronavirus disease 2019. https:// www.who.int/emergencies/diseases/novel-coronavirus-2019/advic e-for-public. Accessed Apr 22020

4. Cook DA, Dupras DM (2004) A practical guide to developing effective web-based learning. J Gen Intern Med 19(6):698-707

5. Gewin V (2020) Five tips for moving teaching online as COVID19 takes hold. Nature 580:295-296

Publisher's Note Springer Nature remains neutral with regard to jurisdictional claims in published maps and institutional affiliations. 